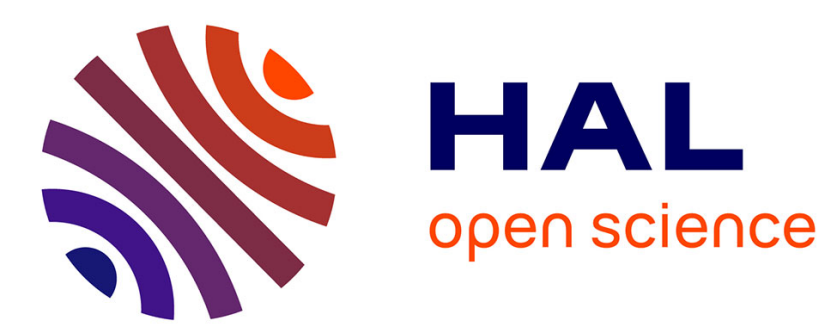

\title{
Dynamic Behavior of Straining in Randomly Packed Beads: Experimental Study
}

Bogdan Muresan, Nadia Saiyouri, Pierre-Yves Hicher

\section{To cite this version:}

Bogdan Muresan, Nadia Saiyouri, Pierre-Yves Hicher. Dynamic Behavior of Straining in Randomly Packed Beads: Experimental Study. Journal of Environmental Engineering, 2013, 139 (5), pp. 692702. 10.1061/(ASCE)EE.1943-7870.0000666 . hal-03283298

\section{HAL Id: hal-03283298 \\ https://hal.science/hal-03283298}

Submitted on 14 Oct 2021

HAL is a multi-disciplinary open access archive for the deposit and dissemination of scientific research documents, whether they are published or not. The documents may come from teaching and research institutions in France or abroad, or from public or private research centers.
L'archive ouverte pluridisciplinaire HAL, est destinée au dépôt et à la diffusion de documents scientifiques de niveau recherche, publiés ou non, émanant des établissements d'enseignement et de recherche français ou étrangers, des laboratoires publics ou privés. 


\title{
Dynamic Behavior of Straining in Randomly Packed Beads: Experimental Study
}

\author{
Bogdan Muresan ${ }^{1}$; Nadia Saiyouri²; and Pierre-Yves Hicher ${ }^{3}$
}

Straining depicts the geometrical retention of fine particles within materials' pore network. Whether or not fines can be retained depends on (1) the structure of materials' pore network as well as (2) fines' size distribution, manner of deposition, and retained amount. In this paper, the main results of straining tests are presented for randomly packed beads filters. The experimental program included a series of tests performed in both dry and water-saturated filters. The tests provided information on the dynamics of fines in the filters' pore network and changes of filters' efficiency. For instance, data supported the existence of four distinct stages: the filling of accessible cavities, the formation then clogging of the preferential pathways, the transfer of fines toward the lateral unobstructed capillaries, and eventual formation of a surface cake. The postulated mechanisms inherent to every single stage are discussed in terms of retention rate, straining length, lateral transfer, and progressive obstruction of constrictions. Additionally, the straining mechanisms were also probed in hydrodynamic conditions at increasing water flows.

Keywords: Granular filters; Fines; Straining; Pore network; Constriction.

\section{Introduction}

Straining results in particle separation strictly by size. Particle separation processes are ubiquitously found in natural and humanaltered soils (e.g., retention of colloidal pollutants and/or internally eroded particles) (McCarthy et al. 1998; Ryan and Elimelech 1996; Simunek et al. 2006; Muresan et al. 2011) as well as in living organisms (e.g., transudation of cells through the blood and lymph capillaries) (Ganter et al. 2006). In the field of technology, the elaboration of a plethora of filters of various designs and specifications has contributed to the development of many industrial and research applications (e.g., separation of mixtures, concentration of products, pollution abatement, and aerosol and dust removal) (Ives 1960, 1970; Yao et al. 1971; Lance and Gerba 1982; Tien 1989; Hubbe 2002; Liu et al. 2007). Due to the applications, considerable attention has shifted to the development of mechanistic separation models (Iwasaki 1937; Friedlander 1958; O’Melia 1965; Mintz 1966; Yao and O'Melia 1968; Ives 1969, 1975a, b; Arun 1970; Payatakes et al. 1974; Rajagopalan and Tien 1976; Tien and Payatakes 1979; Fan et al. 1985; Sharma and Yortsos 1987; Amirtharajah 1988; Rege and Fogler 1988; Elimelech and O'Melia 1990a, b; Tobiason and Vigneswaran 1994; Choo and Tien 1995a; Logan et al. 1995; Stevenson 1997; Bai and Tien 2000a; Ho and Zydney 2000; Lee and Koplik 2001; Odira 2002; Shapiro et al. 2007;

${ }^{1}$ LUNAM Université, Ifsttar, IM, EASE, F-44341 Bouguenais, France (corresponding author). E-mail: bogdan.muresan-paslaru@ifsttar.fr

${ }^{2}$ Ecole Centrale de Nantes, GeM-Institut de Recherche en Génie Civil et Mécanique-UMR CNRS 6183, 1 rue de la Noë, 44321 Nantes Cedex 3, France.

${ }^{3}$ Ecole Centrale de Nantes, GeM-Institut de Recherche en Génie Civil et Mécanique-UMR CNRS 6183, 1 rue de la Noë, 44321 Nantes Cedex 3, France.
Zamani and Maini 2009). In comparison, there is a scarcity of experimental researches and related critical studies on the fundamental mechanisms associated with the transfer of small particles from a mobile phase (i.e., the fines) toward a granular stationary phase (i.e., the filter) (Stanley 1955; Grace 1956; Rajagopalan and Tien 1977; O'Melia and Ali 1978; Pensdse et al. 1978; Payatakes et al. 1981; Ushiki and Tien 1984; Ives 1989; Yongwon and Tien 1992; Moran et al. 1993a, b; Ghidaglia et al. 1991, 1996; Harter et al. 2000; Yoon et al. 2006; Pazmino et al. 2011; Johnson et al. 2011). In other words, if the history of particle separation can be traced by numerically solving a set of microscopic and macroscopic equations (Vigneswaran and Song 1986; Vigneswaran and Tulachan 1988; Elimelech 1994; Duval et al. 2006; Zhu et al. 2007; Stein and Tomas 2012), the obtained results only provide scarce information about the causes and the actual nature of the removal mechanisms.

At a phenomenological level, particle separation in granular fixed beds is commonly viewed as a dynamic process (i.e., a sum of transient mechanisms) (Yoshida and Tien 1985; Choo and Tien 1995b; Kau and Lawler 1995; Bai and Tien 2000b). According to filter/fines size distributions and the filter's pore network structure, either total clogging or indefinite passing of fines may occur. The transition between both evolutions is chaotic because slight changes in fines' trajectories may drastically affect the fate of straining. For instance, during the course of straining, the amount of fines retained within the filter's pore network tends to increase with time. This accumulation may punctually obstruct the capillaries, which eventually lowers the discharge of fines. If sufficient capillaries are clogged and many fines then arrive simultaneously, the latter would form a surface cake that renders in-depth removal inefficient. Actually, there may be no apparent hydromorphological evidence, or only subtle evidence (such as minor changes in the structure of pore network and/or in the course of fines within capillaries), that one or several straining mechanisms develop throughout the filter. Moreover, a filter may lose its in-depth efficiency within the first few instants after evidence of clogging becomes obvious as a sharp decrease of the amount of 
exported fines. Therefore, it is relevant to carefully consider the various mechanisms that take place successively and could be used to portray the dynamic behavior of straining.

In this study, a series of laboratory straining experiments have been carried out on randomly packed beads. Preliminary tests conducted at various filter/fines size distributions and ratios (from $<3$ to up to $>16$ ) pointed out similar trends, thus indicating that the obtained results were likely not specific to the current study but could be observed for several straining conditions. Actually, the examination of (1) the spatial distribution of fines within the filter's pore network and (2) the ability of the filter to collect fines in relationship with the obstruction of interconnections between pores is expected to trace the mechanisms that control the straining. The experiments were performed both in dry and water-saturated filters. This allowed probing how differences between the air and water physicochemical characteristics (i.e., in terms of viscoelastic forces) affect the development of the various mechanisms. This paper, which is restricted to virtually monodisperse granular filters and fines, has three principal objectives. First, establish the straining dynamics as a function of the amount (i.e., in mass) of fines that reach the filter. Second, based on the experimental observations, propose plausible mechanisms explaining the evolutions of the remaining and/or retained fines with respect to their distribution within the pore network. Third, highlight the changes in the straining mechanisms due to the absence/presence of water (flow). Overall, this study lies within the scope of a larger research effort intended to portray the dynamic trait of straining in granular media.

\section{Material and Methods}

\section{Filter Formation}

In the experiments, the retention rates of smaller diameter glass beads (i.e., the fines) were measured within a granular filter of higher diameter glass beads. All the beads were purchased from Sigmund Linder (Warmensteinach, Germany). The straining took place in a transparent tube $0.10 \mathrm{~m}$ in height and $0.10 \mathrm{~m}$ in diameter (i.e., the straining cell) (Fig. 1). The filter consisted of a packing arrangement of 10,000 type $\mathrm{M}$ beads of $3.0 \pm$ $0.1 \mathrm{~mm}$ diameter (average \pm standard deviation). The number of beads was systematically deducted from mass by assuming the regularity of beads' roundness (width/length ratio $\geq 0.98$, as could be verified by random measurements) and density (as confirmed by densitometry measurements, $2.50 \mathrm{~g} \mathrm{~cm}^{-3}$ ). The thickness of the filter was close to $26 \mathrm{~mm}$ (i.e., approximately 11 horizontal layers of beads). In order to permit consistent reproducible filters, the filter was formed in dry conditions with a pluviator by dropping the type $\mathrm{M}$ beads onto diffuser sieves. The pluviator was a tube $0.20-\mathrm{m}$ tall and $0.10 \mathrm{~m}$ in diameter. It was raised automatically every $10 \mathrm{~mm}$ of packing in order to maintain the variations in the drop height low (between 0.10 and $0.09 \mathrm{~m}$ ). To scatter the beads, four diffuser sieves put at $45^{\circ}$ angles to each other were disposed at $0,0.01$, 0.11 , and $0.12 \mathrm{~m}$ from the base of the pluviator. Each sieve had 169 square holes that were $7.7 \mathrm{~mm}$ per side on a 107 by $107 \mathrm{~mm}$ grid pattern. The pluviator generated an average relative density of filters of $62 \pm 4 \%$. More than 80 filters have been pluviated as part of this study, revealing an excellent reproducibility of the filter density.

\section{Porosity Measurements}

Subcentimetric profiles of porosity were determined by the water displacement method on three different filters prepared by the same operator using similar preparation methods. Briefly, tap water was slowly injected from the bottom of the straining cell to progressively saturate all the accessible pores in the filter. From the weight of injected water [density $\sim 1,000 \mathrm{~kg} \mathrm{~m}^{-3} ; 101,325 \mathrm{~Pa}$ (1 atm), $\left.20^{\circ} \mathrm{C}\right]$ and relative height of saturated filter, the volume of pores could be determined. Errors on porosity mainly arose from the precise position of the saturation front $( \pm 0.2 \mathrm{~mm})$, which represented $\sim 4 \%$ of uncertainty on measurements. In general, the water displacement method only provides a lower value for the total volume of pores (as could be calculated from the thickness of the prepared filters, the amount of type $M$ beads, and their size distribution). Actually, both the volumes were comparable (71 $\pm 3 \mathrm{~cm}^{3}$ versus $82 \pm 6 \mathrm{~cm}^{3}$, respectively), thus indicating the importance of the interconnected pores and/or capillaries in the prepared filters. The relative standard deviation (i.e., the absolute value of the coefficient of variation) for porosities was highest toward the bottom and the top of filters: close to $5 \%$, likely due to the change in medium and the partial saturation in the vicinity of the saturation front, respectively.

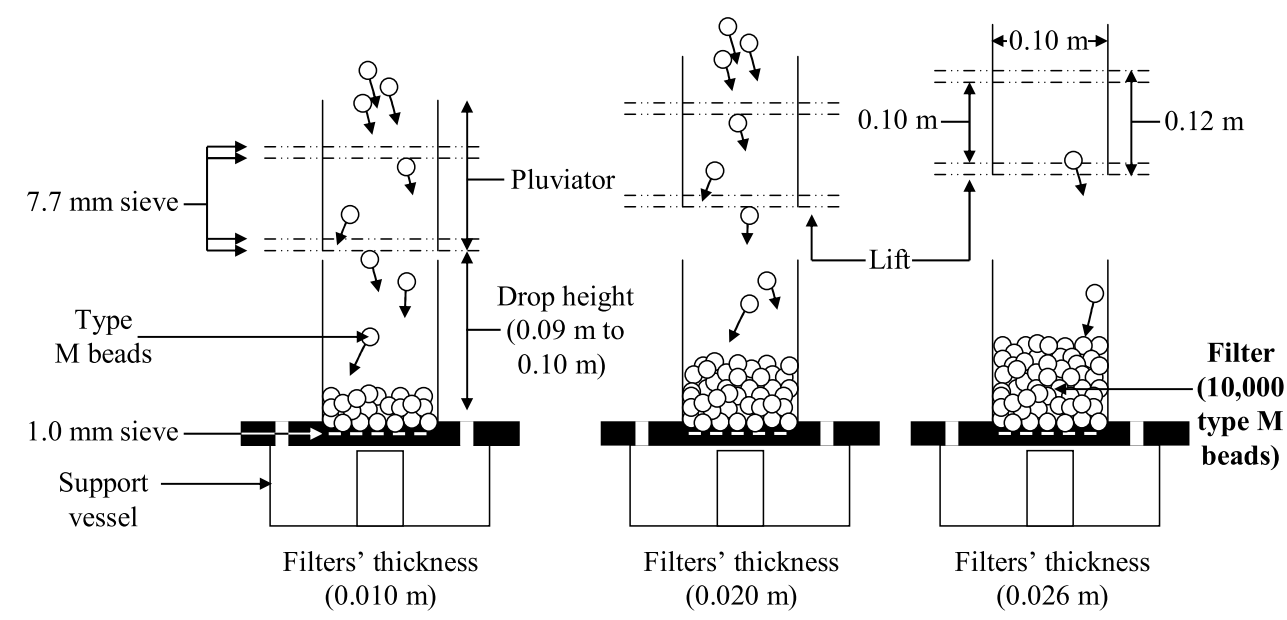

Fig. 1. Material and methods for granular filters' formation; each filter consists of a packing of 10,000 pluviated beads $3.0 \pm 0.1 \mathrm{~mm}$ in diameter; the dimensions and shape of filters were designed so as to achieve reproducible filters and minimize the lateral wall effects 


\section{Straining Procedure}

Straining tests were performed by pouring increasing amounts of fines (type $S$ beads, $0.29 \pm 0.03 \mathrm{~mm}$ in diameter) on pluviated filter (Fig. 2). These were isolated from an initial pool of 0.150 $0.550-\mathrm{mm}$ diameter beads by means of 0.250 and $0.315 \mathrm{~mm}$ sieves. The ratio of type $\mathrm{M}$ beads to type $\mathrm{S}$ beads' diameters (referred to as $\mathrm{D} / \mathrm{d}$ ) was set equal to $\sim 10$. The selected $\mathrm{D} / \mathrm{d}$ ratio value allowed the fines travelling the whole filters' pore network: the minimum constriction formed by three adjacent type $\mathrm{M}$ beads is $\sim 0.15 \mathrm{D}$ (Oger 1987). Additionally, preliminary tests indicated that if $\mathrm{D} / \mathrm{d}>16$, then $90 \%$ of fines make it through the filters, rendering the straining unlikely. In practice, successive loads of fines ( 0.100 g, i.e., 2,800 to 2,900 type $S$ beads) were gently poured onto the central zone of a $0.315 \mathrm{~mm}$ per side square-holed sieve placed $10 \mathrm{~mm}$ above a pluviation device without any contact between them. The fines gradually passed through the sieve as its surface was manually tapped with an iron tip. The pluviator was similar to that used in order to form the filter except for the $7.7 \mathrm{~mm}$ per side square-holed sieves, which were substituted for $1.0 \mathrm{~mm}$ per side square-holed ones. The drop height from the lower diffuser sieve to the top of the granular filter was kept constant at $0.10 \mathrm{~m}$. To minimize the wall effects (i.e., the preferential drainage of fines within the 5-10 D width zone of the filter that borders the straining cell), a circular band of 100-mm outer diameter and 57-mm inner diameter was used as a restrictor. Depending on the amount of fines and in a concern of lowering uncertainties, the straining tests were performed in triplicate or more. The relative standard deviation, calculated on five replicates (including filter preparation, straining procedure, and subsequent sample collection then quantification), was lower than $7 \%$.

\section{Sample Collection}

First, the fraction of fines that passed through the granular filter (i.e., the filtrate) was collected using a cylindrical-shaped bowl separated from the straining system by a $1.0 \mathrm{~mm}$ per side square-holed grid sieve. A cup was placed within the central zone of the bowl that lies underneath the grid. This allowed the distinction between the filtrate that spilled out in the central (i.e., 57-mm diameter disk) and lateral (57 to $100-\mathrm{mm}$ circular band) zones of the filter. Next, in order to determine the fraction of fines retained in the granular matrix of the filter (i.e., the retentate), the straining system was carefully displaced from the filtrate-receiving bowl/cup to another similarly prepared support vessel. The central zone retentate was caused to move vertically downward by repeatedly plunging a thin metal rod into the filter. Once all the central zone retentate has been transferred into the cup of the second vessel, an L-shaped thin metal rod was employed in order to draw the lateral zone retentate into the bowl. Last, the fraction of fines trapped on top of the restrictor was separately collected by vigorously shaking the straining system. Mass balance calculations pointed out very low losses of fines during the straining tests $(<1 \%)$.

\section{Straining Procedure in Water-Saturated Filters}

The experimental program also included a series of straining tests performed in water-saturated filters both in the absence (i.e., hydrostatic) or presence (i.e., hydrodynamic) of water $[\mathrm{pH}=7.6$, hardness $=160$ parts per million(ppm)] flow. In these tests, the collection devices and prepared filter were carefully submersed in a water basin up to the restrictor, i.e., approximately $1 \mathrm{D}$ above the filter (Fig. 2). The same straining procedure as previously described was then applied. As regards the hydrodynamic tests, a water input was set into the straining cell ( $0.05 \mathrm{~m}$ above the filter). The output consisted of a hole within the water basin at the same height as the restrictor. The flow of injected water equaled 0.52 , 1.07 , or $2.00 \mathrm{~L} \mathrm{~min}^{-1}$, i.e., $(1.10,2.27$, or 4.25$) \times 10^{-3} \mathrm{~m} \mathrm{~s}^{-1}$, as Darcy velocities. To limit turbulences and structural derangement of the filter, a semicylindrical sheet of metal was used to deflect the water jet along the walls of the straining cell. Once the water flow stabilized (i.e., the inputs equaled outputs, up to $3 \mathrm{~min}$ ), the fines were poured. The filtrate and retentate relative to both the central and lateral zones of the filters as well as the fines onto the restrictor were collected then dried at $105^{\circ} \mathrm{C}$ for $24 \mathrm{~h}$. Finally, the amount of fines in each fraction was determined by using an analytical balance with $10^{-4} \mathrm{~g}$ precision. The overall procedure resulted in relative standard deviations lower than $10 \%$ (i.e., increased with the water flow).

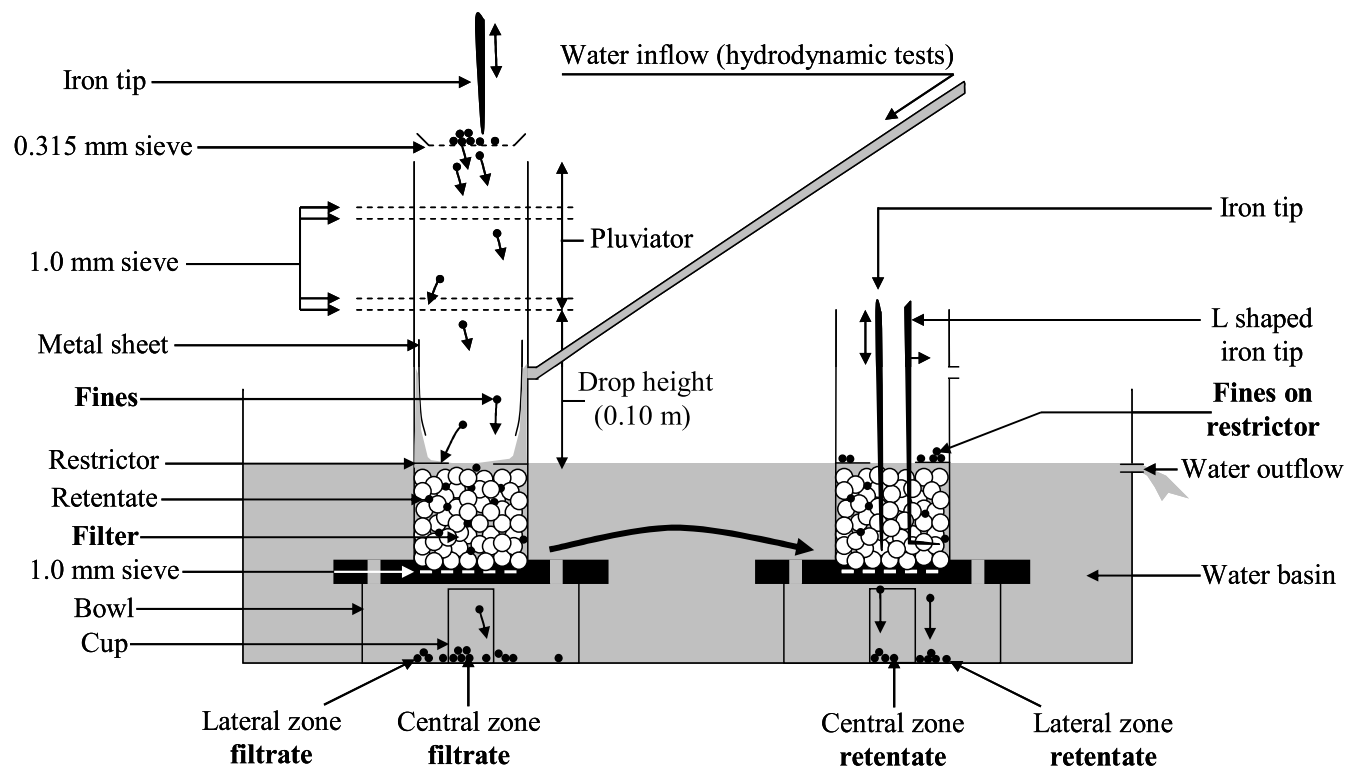

Fig. 2. Straining procedure for saturated filters, either in the absence (i.e., hydrostatic) or presence (i.e., hydrodynamic) of water flow; a similar procedure was used for dry filters; both the dry and saturated filters were initially formed in dry conditions 


\section{Mathematical Formulation}

\section{Retention Rate and Straining Length Calculation}

The obtained data consisted of the retained and filtered amounts of fines (i.e., number of type $\mathrm{S}$ beads) that traveled through the central and/or lateral zones of the filter. Another datum was the amount of fines deposited onto the restrictor. Hence, the retention rate for the central zone $\left[r_{C}\right.$, Eq. $\left.(1 a)\right]$ was formulated as the ratio of the amount of retentate in the central zone to the total amount of fines once the fractions associated with the restrictor and lateral zone have been deducted. An analogous formula could be written for lateral retention rate $\left[r_{L}\right.$, Eq. $\left.(1 b)\right]$.

$$
r_{C}(\%)=\frac{R_{C}}{T-N-F_{L}-R_{L}}
$$

and

$$
r_{L}(\%)=\frac{R_{L}}{T-N-F_{C}-R_{C}}
$$

where $R=$ amount of retentate; $F=$ amount of filtrate; $T=$ total amount of fines poured during the straining test; and $N=$ amount of fines deposited onto the restrictor. The subscripts $C$ and $L$ stand for the central and lateral zones of the filter, respectively. Based on the mass balance equation, i.e., $T=N+R_{C}+R_{L}+F_{C}+F_{L}$, Eqs. (1a) and (1b) can be reformulated as

$$
r_{C}(\%)=\frac{R_{C}}{F_{C}+R_{C}}
$$

and

$$
r_{L}(\%)=\frac{R_{L}}{F_{L}+R_{L}}
$$

In Eqs. (2a) and (2b), $r_{C}$ and $r_{L}$ only depend on the amounts of fines that spilled out and were retained in the central and lateral zone of filters, respectively. From the shape of the $r_{C}$ and $r_{L}$ profiles (the pace of straining slowed at depth, see "Porosity and straining profiles"), it has been assumed that there is a logarithmic dependence between the amount of filtrate and the straining length (i.e., $\lambda$ ) and the thickness of filters, $\Delta x$ (in layers of type $\mathrm{M}$ beads).

$$
e^{-\Delta x / \lambda_{C}}=\frac{F_{C}-0.25\left(F_{L}+R_{L}\right)}{T-N}
$$

While considering the straining length in the central zone (i.e., $\lambda_{C}$ ), the 0.25 coefficient stands for the proportion of the central zone filtrate that traveled through the lateral zone. The value of the coefficient was experimentally determined from the straining profiles by measuring at increasing depths the changes in the amount of fines that used the lateral zone. The value of the coefficient increased with the filters' thickness, whereas it remained relatively unchanged as a function of the amount of fines that reached the filters (data not shown). By analogy with the scattering of a beam of particles, $\lambda_{C}$ provides an estimation of the distance covered by the central zone fines before being stopped, whereas $r_{C}$ depicts the fines retained in the central zone of filter (that may have traveled throughout the lateral zone), $\lambda_{C}$ depicts the fines that only passed through the central zone (the lateral zone contribution being deducted). It is therefore expected to trace changes in the central zone efficiency of formed filters.

\section{Estimating the Obstruction of Constrictions}

While probing the retention rates, one may rather follow the progressive obstruction of pore sections than the filling of cavities or the amount of retentate. For instance, the ability of filters to transmit the fluid of fines is driven by the dimensions of constrictions (i.e., the small windows between interconnected pores). Changes in the dimensions of constrictions could be traced by monitoring the available pore section area for the passing of fines. It is assumed that the filters' type $\mathrm{M}$ beads are regularly disposed so as to form 11 distinct horizontal layers (initially, to study the structure of filters, these were formed by pluviating successive loads of 800 to 930 type $\mathrm{M}$ beads, also allowing probing the straining properties of every single layer). Another hypothesis is that the fines are primarily filtered in the immediate vicinity of the smallest constrictions connecting two superimposed pores that constitute the steeply dipping pathways. Accordingly, the unoccupied area (i.e., $A_{s}$ ) obtained when cutting each layer into halves (i.e., horizontal planes of maximum relative density) was deterministically formulated as the area of the inner surface of the restrictor that is neither filled by type $\mathrm{M}$ beads nor by the retentate (Fig. 3).

$$
A_{S}\left(\mathrm{~cm}^{2}\right)=\frac{\pi}{4}\left(l^{2}-j_{S} \mathrm{D}^{2}-k_{S} \mathrm{~d}^{2}\right)
$$

where $l$ (in centimeters) $=$ length of the inner diameter of restrictor; and $j_{s}$ and $k_{s}=$ corresponding number of central zone type $\mathrm{M}$ beads and retentate (as determined from the preliminary filters' formation studies and the straining experiments), respectively. The subscript $s$ stands for the position of the horizontal layer within the 1 (top)-11 (bottom) interval. Additionally, $j_{s}$ was calculated from the volume of the layer (i.e., $h \pi / 4 l^{2}$ ), relative density (i.e., $1-n_{S}$ ), and the volume of a type $\mathrm{M}$ bead (i.e., $\pi / 6 \mathrm{D}^{3}$ ) as follows:

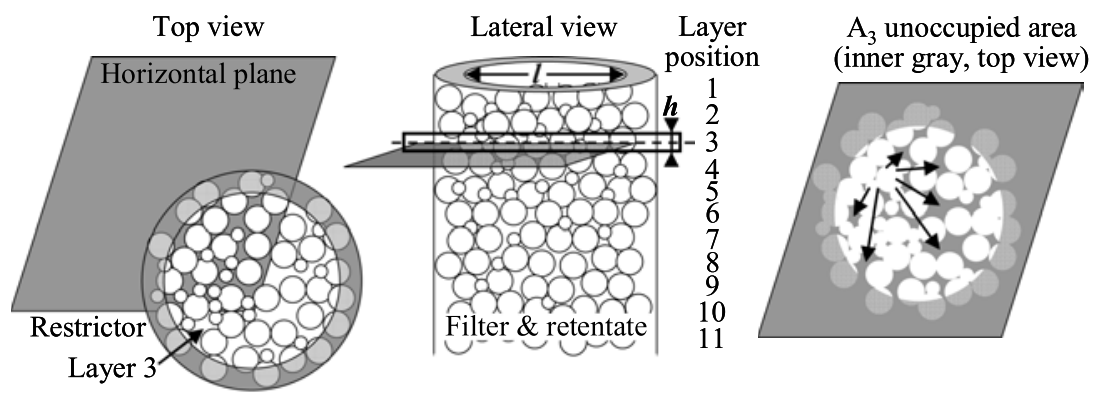

Fig. 3. Horizontal plane cutting into half the third layer of a granular filter (the left-hand and central panels correspond to the top and lateral views, respectively); the resulting central area unoccupied by type $\mathrm{M}$ beads and the retentate, i.e., $A_{3}$ (inner grey zone), is shown at the right 


$$
j_{S}=\frac{3 l^{2} h\left(1-n_{S}\right)}{2 \mathrm{D}^{3}}
$$

where $h=$ thickness of the layer $(0.24 \pm 0.01 \mathrm{~cm})$; and $n_{S}=$ porosity (as measured using the water displacement method). By plugging Eq. (5) into Eq. (4), the unoccupied area associated with every single layer of filter was formulated as the subsequent function:

$$
A_{S}\left(\mathrm{~cm}^{2}\right)=\frac{\pi}{4}\left[l^{2}\left(1-\frac{3 h\left(1-n_{S}\right)}{2 \mathrm{D}}\right)-k_{S} \mathrm{~d}^{2}\right]
$$

Once the unoccupied area is known, the average area of constrictions (i.e., $C_{S}$ ) is set equal to the value of the $A_{s} / j_{s}$ ratio [Eq. (7)]. As a matter of fact, within the horizontal planes of maximum relative density, one can pair every single type $M$ bead with a unique constriction.

$$
C_{S}\left(\mathrm{~cm}^{2}\right)=\frac{\pi \mathrm{D}^{2}}{4}\left[\frac{2 \mathrm{D}}{3 h\left(1-n_{S}\right)}\left(1-k_{S} \frac{\mathrm{d}^{2}}{l^{2}}\right)-1\right]
$$

The total unoccupied area (i.e., $A=\sum_{S=1}^{11} A_{S}$ ) and $C_{S}$ increase with porosity. These decrease with the amount of retentate and relative thickness of each layer (i.e., $h / \mathrm{D}$ ratio). The validity of the provided formula is restricted to a reasonable range of $n_{s}$ values, i.e., from 0.25 to 0.50 . Additionally, $h$ is a complex function of $l, \mathrm{D}$, and type $\mathrm{M}$ beads packing, which was not explicitly taken into account in calculations. Finally, because it has been assumed that fines are primarily filtered within horizontal planes of maximum relative density, the calculated $A$ and $C_{S}$ values likely underestimate the actual corresponding areas.

\section{Results and Discussion}

\section{Porosity and Straining Profiles}

The porosity of filters, as determined using the water displacement method, averaged $0.35 \pm 0.05$ [ $n=3$, Fig. 4(a) ]. It decreased from $0.40 \pm 0.02$ near the top of the filters to $0.27 \pm 0.02$ near the bottom of the filters. The $C_{S}$ value simultaneously decreased from $(3.2 \pm 0.2) \times 10^{-2} \mathrm{~cm}^{2}$ down to $(1.2 \pm 0.1) \times 10^{-2} \mathrm{~cm}^{2}$ [Fig. 4(b)]. This demonstrates the existence of an in-depth densification mechanism that probably took place during the filters' formation. This was manifest through orderly packing of deepest type $M$ beads: the porosity of the 1-3 lowest layers approached that of the dense arrangement of equal spheres ( 0.259) (Oger 1987).

The densification mechanism had limited effects on the indepth straining dynamics. Preliminary measurements confirmed the increase of the cumulative $r_{C}$ with the thickness of filters [Fig. 5(a)]. Yet the finite-difference approximation of its derivative (i.e., $\left.\Delta\left(r_{C}\right) / \Delta s\right)$ was highest within the 1-3 uppermost layers [Fig. 5(b)]. This was especially true for the saturated filters: the $\Delta\left(r_{C}\right) / \Delta s$ value was $2.5 \pm 0.5 \%$ layer $^{-1}$ near the top of dry filters, whereas it reached up to $10.4 \pm 2.2$ and $28.2 \pm 1.3 \%$ layer $^{-1}$ in the hydrodynamic (water flow of $1.07 \mathrm{~L} \mathrm{~min}^{-1}$ ) and hydrostatic straining tests, respectively. Accordingly, $\lambda_{C}$ of the 1-3 uppermost layers of the dry and the saturated (hydrodynamic and hydrostatic tests) filters were 2.1-5.7, 2.2-4.7, and 1.7-3.9 layers, respectively, and gradually increased up to $13.9 \pm 1.0,8.0 \pm 0.5$, and $6.5 \pm 0.2$ near the bottom [Fig. 5(c)]. The in-depth distance covered by fines prior to immobilization is lowest in the 1-3 uppermost layers, i.e., presumably due to the concomitant arrival of many pluviated fines, which are retained when being simultaneously driven downward

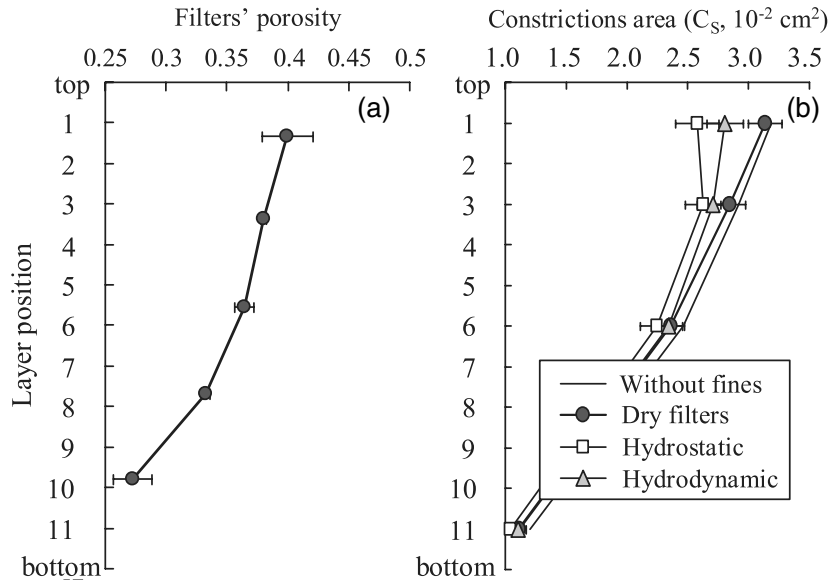

Fig. 4. Vertical profiles of (a) porosity and (b) area of constrictions; constrictions data consist of averaged values relative to the filters' central zone horizontal planes of maximum relative density; the dotted line in (b) presents the area of constrictions in the absence of retentate (i.e., without fines); the dry, hydrostatic, and hydrodynamic profiles were obtained by pluviating 42,500 fines; error bars account for the relative standard deviation, $n=3$
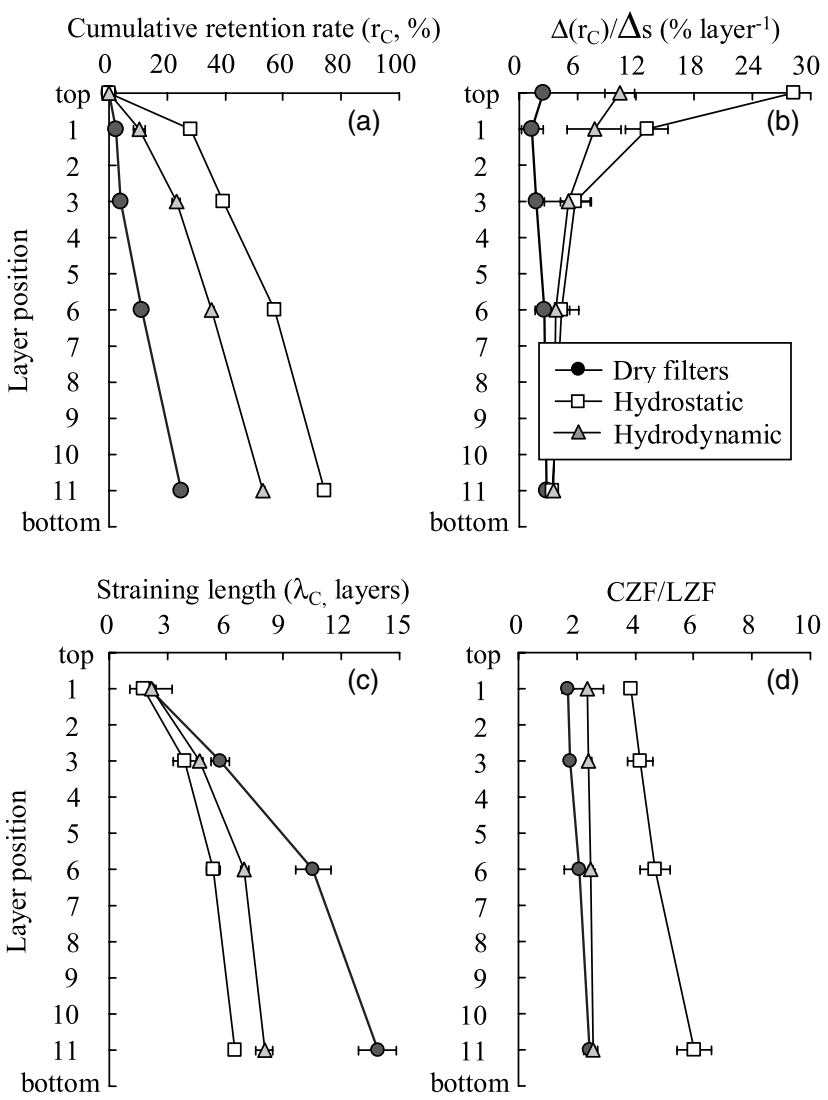

Fig. 5. Vertical profiles of (a) retention rate, (b) finite-difference approximation of retention rate derivative, (c) straining length, and (d) central/lateral zone fines in dry and water-saturated (both hydrostatic and hydrodynamic) filters; unlike (b) and (c) that provide local data, (a) and (d) display the cumulative increase of the retention rate and central/lateral zones fines as functions of the thickness of filters; data were obtained by pluviating 42,500 fines; error bars account for the relative standard deviation, $n=3$ 
through a limited number of superficial central zone constrictions. Put differently, the gained figures pointed out that straining mechanisms developed early during the passing through of the fines and thereafter, in spite of the in-depth densification, remained relatively uniform.

Another observation that supported the limited impact of the indepth densification originated from the distribution of fines within the filters' pore network. The value of central zone fines (CZFs) (i.e., the sum, in number of fines, of the central zone filtrate and retentate) to lateral zone fines (LZFs) (i.e., the sum, in number of fines, of the lateral zone filtrate and retentate) ratio progressively increased with the thickness of the filters [Fig. 5(d)]. By analogy with the lateral propagation of stresses during the vertical loading of granular materials (i.e., through force chains, and likely due to the reciprocal distribution of contacts and constrictions between grains), the central zone fines were readily dispersed as they plunged into the filters' pore network. The LZFs from the 1-3 uppermost layers stood for $20-37 \%$ of fines once the fraction trapped onto the restrictor has been deducted. This early lateral dispersion was most pronounced within the dry filters (i.e., of the lowest $\mathrm{CZF} / \mathrm{LZF}$ value). Further at depth, despite the in-depth densification, $25 \pm 2 \%$ of LZF was redirected into the central zone (both in the dry and water-saturated filters). Accordingly, the dynamics of straining in the formed filters were extensively driven by near-top fine-fine and/or fine-filter interactions.

\section{Monitoring of Straining Mechanisms in Dry Filters}

Figs. 6(a-c) show the evolution of $r_{C}, \lambda_{C}$, and the CZF/LZF ratio for the straining tests conducted on dry filters. These were plotted against the occupation by fines of horizontal planes of maximum relative density: $\Delta A / A_{0} ; \Delta A=A_{0}-A$, where $A_{0}$ is the total unoccupied area. In this formulation, $A_{0}$ was determined from the number of type $\mathrm{M}$ beads constitutive of every single filter layer and the corresponding porosities using Eq. (6) in the absence of retentate, i.e., $A_{0}=\sum_{S=1}^{11} A_{0, S}=66 \pm 4 \mathrm{~cm}^{2}$. The $r_{C}$ curve varied between $21 \pm 1 \%$ and $46.5 \pm 0.4 \%$. It featured four stages: (1) an early high variability stage $\left(0<\Delta A / A_{0}<4 \%\right)$, (2) a subsequent stage of lower $r_{C}$ values (at $\Delta A / A_{0} \sim 4 \%$ ), (3) a later stage of rapid $r_{C}$ increase $\left(5<\Delta A / A_{0}<23 \%\right)$, and (4) a final stage of steady $r_{C}$ increase $\left(23<\Delta A / A_{0}<100 \%\right)$. Beyond this limit $\left(\Delta A / A_{0}>100 \%\right)$, the straining within the central zone of the filters was no longer efficient.

Initially, at $\Delta A / A_{0} \sim 0$, the fines could broadly explore the filters' pore network. The average area of the central zone constrictions in the horizontal planes of maximum relative density was (1-3) $\times 10^{-2} \mathrm{~cm}^{2}$ [same magnitude as $A_{0, s} / j_{s}$, Fig. 4(b)]. This allows the simultaneous passing through of 15-35 fines, which represents up to 5,000-10,000 fines per layer [the average area of fines' cross section equaled $\left.(0.066 \pm 0.008) \times 10^{-2} \mathrm{~cm}^{2}\right]$. Once below the 1-3 uppermost layers of intense lateral dispersion, the central zone fines mainly propagated in-depth, i.e., both $\lambda_{C}$ and CZF/LZF curves exhibited localized maxima (12.6 \pm 0.3 layers and $2.2 \pm 0.2$, respectively). However, due to the limited influence of wall effects, the straining in the central zone was significantly higher than that in the lateral zone of filters: $29 \pm 2 \%$ versus $24 \pm 3 \%$. From an engineering point of view, this initial stage corresponds to the straining of diluted granular fluids through a large-size filter.

As the amount of retentate increased $\left(0<\Delta A / A_{0}<4 \%\right), r_{C}$ exhibited marked variations $\left(\Delta r_{C}\right.$ up to $\left.10 \pm 1 \%\right)$. These accompanied a lowering of $\lambda_{C}$ and CZF/LZF ratio value (down to $9.7 \pm 0.9$ layers and $1.4 \pm 0.2$, respectively). Accordingly, this straining stage was depicted by fluctuating straining dynamics that
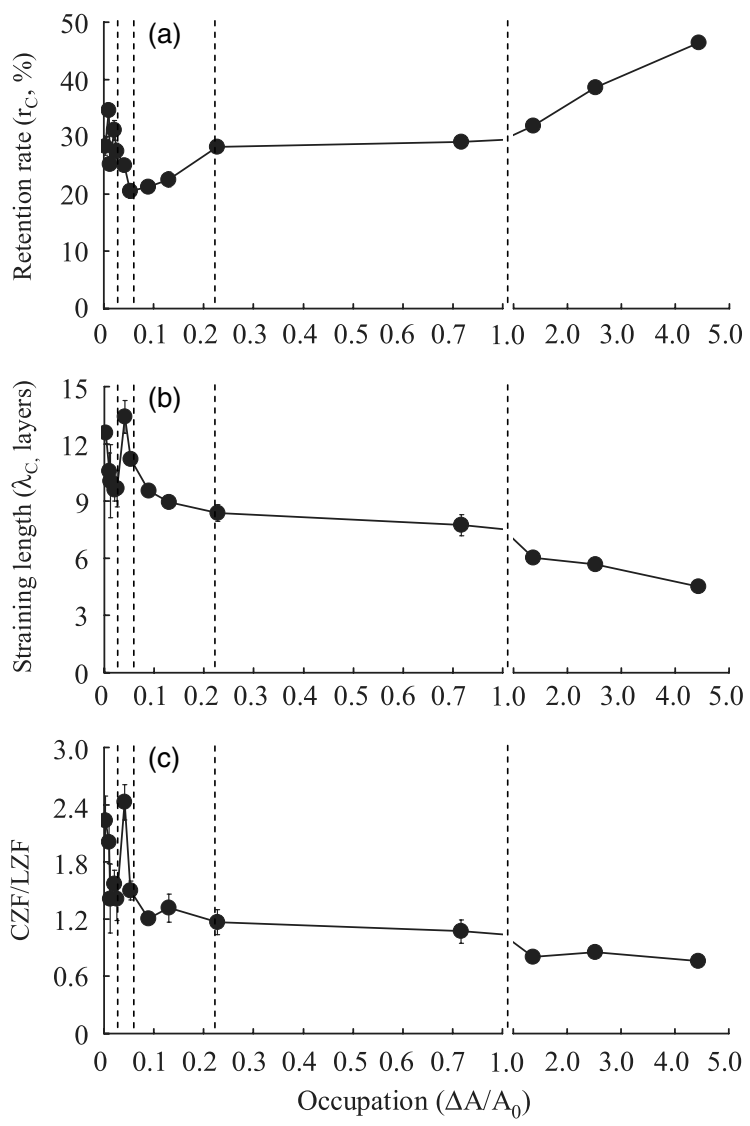

Fig. 6. Evolution of (a) retention rate, (b) straining length, and (c) central/lateral zone fines; these were plotted against the occupation of the horizontal planes of maximum relative density by retentate (a proxy of the progressive obstruction of constrictions); the tests were conducted in dry filters; the vertical dotted lines delimit straining stages; error bars account for the relative standard deviation, $n \geq 3$

overall lowered the straining length for central zone fines and favored the transfer of CZF toward the lateral zone. At $\Delta A / A_{0} \sim 4 \%$, a definite peak of $\lambda_{C}$ [up to $13.4 \pm 0.8$ layers, $\partial\left(\lambda_{C}\right) / \partial\left(\Delta A / A_{0}\right)=230$ layers] and of the $\mathrm{CZF} / \mathrm{LZF}$ ratio [up to $\left.2.4 \pm 0.1, \partial(\mathrm{CZF} / \mathrm{LZF}) / \partial\left(\Delta A / A_{0}\right)=40\right]$ preceded a fall of the $r_{C}$ values [down to $21 \pm 1 \%, \partial\left(r_{C}\right) / \partial\left(\Delta A / A_{0}\right)=-250 \%$ ]. Put differently, the filtrate concentrated in the central zone, while the dynamics of central zone straining decreased. Two hypotheses were advanced to account for this observation. The first concerned the formation of steeply dipping preferential pathways in the central zone of filters. The second assumed that the flow of fines bypassed a large portion of this zone. Actually, in spite of the increasing amounts of retained fines $\left(R_{C}=3,800 \pm 140\right.$ fines), $\lambda_{C}$ was maximal. This signifies that the filtered fines punctually facilitate the passing through of the incoming ones. It is possible that a substantial fraction of the CZF filled up the closed capillaries, i.e., the cavities. The remaining unobstructed capillaries would then form a network of steeply dipping preferential pathways in the central zone of the filters. Numerical simulations presented in Tien (1989) corroborated the results. These pointed out the existence of an early stage of short pass-through duration for exported fines. As regards the bypass mechanisms, $38 \pm 3 \%$ of the fines that reached the filters at $\Delta A / A_{0} \sim 4 \%$ were transferred into the lateral zone within the 1-3 uppermost layers. Concomitantly, toward the bottom of the filters, $1 / 4$ of the LZF was redirected into the central zone (see "Porosity and straining profiles"). The corresponding 
values of the $\mathrm{CZF} / \mathrm{LZF}$ ratios were $1.7 \pm 0.3$ and $2.4 \pm 0.2$, respectively. The latter value matched well the magnitude of $\mathrm{CZF} / \mathrm{LZF}$ ratio peak, thus supporting the bypass mechanism hypothesis. Overall, both the mechanisms seemingly acted to lower the efficiency of straining through the formation of the central zone steeply dipping preferential pathways and use of lateral zone capillaries.

At $5<\Delta A / A_{0}<23 \%$, following the minimum of straining, $r_{C}$ markedly increased [up to $28.3 \pm 0.3, \partial\left(r_{C}\right) / \partial\left(\Delta A / A_{0}\right)=$ $40 \%]$. This accompanied a fall of the $\mathrm{CZF} / \mathrm{LZF}$ ratio values [down to $1.2 \pm 0.1, \partial(\mathrm{CZF} / \mathrm{LZF}) / \partial\left(\Delta A / A_{0}\right)=-2$ ]. Later, at $23<\Delta A / A_{0}<100 \%$, the increase of $r_{C}$ decelerated $\left[\partial\left(r_{C}\right) /\right.$ $\partial\left(\Delta A / A_{0}\right)<3 \%$ ] and the $\mathrm{CZF} / \mathrm{LZF}$ ratio went on decreasing until below unit values were reached. Accordingly, as the amount of retentate in the central zone of filters increased, the transfer of fines toward the lateral zone and use of local capillaries became prevalent. While entering the filters, the percentages of fines transferred from the central zone to the lateral zone were $38 \pm 3 \%, 46 \pm 4 \%$, and $52 \pm 2 \%$ at $\Delta A / A_{0}=5,23$, and $100 \%$, respectively. This can be explained by the clogging and subsequent filling of the central zone steeply dipping preferential pathways. For instance, providing a steeply dipping preferential pathway is clogged, and in the absence of major structural changes, the central zone fines will locally accumulate (i.e., marked $r_{C}$ increase) until some lateral capillary becomes accessible (i.e., slower $r_{C}$ increase). This would in turn stabilize the pace of the central zone straining. The previously mentioned sequence of straining mechanisms was supported by the fact that at $5<\Delta A / A_{0}<23 \%, \lambda_{C}$ markedly decreased [down to $8.4 \pm 0.4$ layers, $\partial\left(\lambda_{C}\right) / \partial\left(\Delta A / A_{0}\right)=-30$ layers], then at $23<\Delta A / A_{0}<100 \%, \lambda_{C}$ went on decreasing, but at a slower pace [ $<7$ layers, $\partial\left(\lambda_{C}\right) / \partial\left(\Delta A / A_{0}\right)=-2$ layers]. From an engineering point of view, this means that the central zone steeply dipping preferential pathways are transient structures, which $\sim 5 \%$ of horizontal planes of maximum relative density occupation sufficed to $\operatorname{clog}$.

Finally, at $\Delta A / A_{0}>100 \%$, most of the central zone constrictions were thought to be clogged by fines. This was apparent by sight because the fines formed a surface cake on top of the filters. Another observation was the slower increase of the amounts of central zone filtrate: $\partial\left(F_{C}\right) / \partial\left(\Delta A / A_{0}\right)$ decreased from $185 \times 10^{3}$ to $50 \times 10^{3}$ type $S$ beads. Concomitantly, the amounts of filtrate collected in the lateral zone kept on increasing steadily: $\partial\left(F_{L}\right) / \partial\left(\Delta A / A_{0}\right)=(190 \pm 30) \times 10^{3}$ type $S$ beads. This resulted in close to floor values for $\lambda_{C}$ and the $\mathrm{CZF} / \mathrm{LZF}$ ratio (5.4 \pm 0.8 layers and $0.2 \pm 0.1$, respectively). Overall, these figures indicated that (1) in-depth straining was no longer efficient, and (2) once most of the central zone constrictions were obstructed, $57 \pm 3 \%$ of the fines that reached the filter were driven into the lateral zone.

\section{Monitoring of Straining Mechanisms in Water-Saturated Filters}

Figs. $7(\mathrm{a}-\mathrm{c})$ exhibit the evolution in saturated filters (hydrostatic conditions) of $r_{C}, \lambda_{C}$, and the $\mathrm{CZF} / \mathrm{LZF}$ ratio as functions of the occupation of horizontal planes of maximum relative density. Contrary to expectations, the values of $r_{C}$ and the $\mathrm{CZF/LZF}$ ratio were higher than in the dry filters: $85 \pm 7 \%$ and $3.3 \pm 1.2$, respectively. As a result, $\lambda_{C}$ was $60 \pm 9 \%$ lower than in the dry filters: 3.1-6.5 layers versus 4.5-13.4 layers. This indicated that the fines hardly made it to both the lateral zone and the output of filters. Two mechanisms were proposed to account for this observation. The first one supposed that the fines accumulated in central zone cavities heedless of the accessible lateral capillaries. The second one presumed the existence of unstable equilibria for fines


Fig. 7. Evolution of (a) retention rate, (b) straining length, and (c) central/lateral zone fines; these were plotted against the occupation of the horizontal planes of maximum relative density by retentate (a proxy of the progressive obstruction of constrictions); the tests were conducted in water-saturated filters, hydrostatic conditions; the vertical dotted lines delimit straining stages; error bars account for the relative standard deviation, $n \geq 3$

(e.g., type $\mathrm{S}$ beads lying on top of type $\mathrm{M}$ beads). Preliminary tests conducted on hand-vibrated filters provided similar $r_{C}$ values (i.e., $73 \pm 1 \%$ versus $75 \pm 2 \%$ ), thus making the last hypothesis unlikely. Hence, it is possible that viscous forces acted to lower the kinetic energy of the fines. This would (1) limit their bounce in the central zone capillaries and eventually their lateral dispersion, and (2) favor the group effects, e.g., the clogging of the central zone constrictions during the sedimentation of clusters of fines. The importance of viscous forces and the existence of group effects was manifest when increasing water velocity in the hydrodynamic straining tests (from 0 to $4.25 \times 10^{-3} \mathrm{~m} \mathrm{~s}^{-1}$ ). The value of $r_{C}$ and the $\mathrm{CZF} / \mathrm{LZF}$ ratio decreased from $75 \pm 2 \%$ to $48 \pm 2 \%$ and from $6.0 \pm 0.9$ to $2.5 \pm 0.5$, respectively (Table 1). Concomitantly, $\lambda_{C}$ increased from $5.7 \pm 0.3$ layers to $7.4 \pm 0.7$ layers. Accordingly, the flow of water guided a notable fraction of fines throughout the filters' pore network. This limited the occupation of the horizontal planes of maximum relative density [at $1.10 \times$ $10^{-3} \mathrm{~m} \mathrm{~s}^{-1}$ and $\Delta A / A_{0}=15 \%, C_{S}$ was $5-10 \%$ higher than in hydrostatic straining tests, Fig. 4(b)] and augmented the transfer of central zone fines towards the lateral zones of filters.

The $r_{C}$ and $\mathrm{CZF} / \mathrm{LZF}$ ratio decreases primarily occurred at low Darcy velocities $\left(<1.10 \times 10^{-3} \mathrm{~m} \mathrm{~s}^{-1}\right.$ and $-14.5 \pm 0.8 \%$ and $-2.8 \pm 0.5$ per $10^{-3} \mathrm{~m} \mathrm{~s}^{-1}$, respectively) then stabilized at higher velocities (between $2.27 \times 10^{-3}$ and $4.25 \times 10^{-3} \mathrm{~m} \mathrm{~s}^{-1}$ and $-2.4 \pm 0.2 \%$ and $>-0.1 / 10^{-3} \mathrm{~m} \mathrm{~s}^{-1}$, respectively). The 
Table 1. Evolution of Filtration Characteristics as Depicted by $r_{C}$, CZF/LZF, $\lambda_{C}$, and $C_{S}$ in Water-Saturated Filters as Functions of Darcy Velocity

\begin{tabular}{lccc}
\hline $\begin{array}{l}\text { Filtration test } \\
\text { (Darcy velocity) }\end{array}$ & $\begin{array}{c}\text { Hydrostatic } \\
\left(0 \mathrm{~ms}^{-1}\right)\end{array}$ & $\begin{array}{c}\text { Hydrodynamic } \\
\left(1.1010^{-3} \mathrm{~ms}^{-1}\right)\end{array}$ & $\begin{array}{c}\text { Hydrodynamic } \\
\left(2.2710^{-3} \mathrm{~ms}^{-1}\right)\end{array}$ \\
\hline Retention rate $\left(r_{C}\right)(\%)$ & $75 \pm 2$ & $58 \pm 2$ & $53 \pm 1$ \\
CZF/LZF & $6.0 \pm 0.9$ & $2.9 \pm 0.5$ & $2.6 \pm 0.1$ \\
Straining length $\left(\lambda_{C}\right)$ (layers) & $5.7 \pm 0.3$ & $6.7 \pm 0.5$ & $7.8 \pm 0.2$ \\
$C_{S}($ test $) / C_{S}$ (hydrostatic) & 1.00 & $1.04-1.07$ & $1.05-1.10$ \\
\hline
\end{tabular}

Note: The values are provided as average \pm standard deviation $(n=3)$.

same pattern was observed for $\lambda_{C}$ : it markedly increased at $<1.10 \times 10^{-3} \mathrm{~m} \mathrm{~s}^{-1}\left(0.9 \pm 0.4\right.$ layers $\left./ 10^{-3} \mathrm{~m} \mathrm{~s}^{-1}\right)$ then stabilized between $2.27 \times 10^{-3}$ and $4.25 \times 10^{-3} \mathrm{~m} \mathrm{~s}^{-1} \quad(<0.2$ layers/ $\left.10^{-3} \mathrm{~m} \mathrm{~s}^{-1}\right)$. This signifies that relatively low water velocities sufficed to increase the dispersion of fines, thereby minimizing the group effects and ultimately enhancing their passing through the filters' pore network. Inversely, even at the highest Darcy velocity $\left(4.25 \times 10^{-3} \mathrm{~m} \mathrm{~s}^{-1}\right)$, the $r_{C}$ values were invariably higher than in the dry filters $(48 \pm 2 \%$ versus $25.0 \pm 0.3 \%)$. The background flow did not suffice to counterbalance the water-induced straining effects. It is possible that by repeatedly channeling the fines though the same pathways (i.e., the capillaries concentrating the streamlines), the water flow may have acted to locally clog the filters. This was supported by the lower straining lengths in the water-saturated filters: $7.4 \pm 0.7$ layers versus $13.4 \pm 0.8$ layers in the dry filters. Actually, higher Darcy velocities may result in lower straining rates, i.e., even lower than in dry filters. Further research is nevertheless needed to confirm this hypothesis.

The identified stages (see "Monitoring of Straining Mechanisms in Dry Filters") covered a higher magnitude of $\Delta A / A_{0}$ values in the straining tests conducted on saturated filters (hydrostatic) than on dry filters (Figs. 6 and 7). They stretched toward higher $\Delta A / A_{0}$ values. Depending on straining stage, the occupation of horizontal planes of maximum relative density was two to three times higher for saturated filters [up to 8-12 times higher if assuming that the fines were mostly retained in the 1-3 uppermost layers, Fig. 4(b)]. Accordingly, both the amplitude of central zone straining and the amount of retentate needed in order to achieve clogging were higher: $>13,900 \pm 500$ fines for the saturated filters versus $>3,800 \pm 140$ fines for the dry filters. This apparent contradiction suggests that the fines from central zone cavities were no longer retained in the horizontal planes of maximum relative density: $\Delta A / A_{0}$ increased too fast. These would instead pile up, which kept a large proportion of the central zone constrictions and therefore of the adjoining unobstructed capillaries from further clogging. In detail, the filling of the central zone cavities $\left(0<\Delta A / A_{0}<15 \%\right)$ was associated to relatively high $r_{C}$ (between $76 \pm 2 \%$ and $82 \pm 2 \%$ ) and $\lambda_{C}$ (between $4.2 \pm 0.3$ layers and $4.9 \pm 0.4$ layers) values, and increasing $\mathrm{CZF} / \mathrm{LZF}$ ratios $\left[\partial(\mathrm{CZF} / \mathrm{LZF}) / \partial\left(\Delta A / A_{0}\right)=20\right]$. The fines were efficiently retained in the uppermost layers of the central zone of filters. At $\Delta A / A_{0}=15 \%$, the $\mathrm{CZF} / \mathrm{LZF}$ ratio experienced marked increases [from $4.2 \pm 0.3$ to $6.0 \pm 0.9$, $\partial(\mathrm{CZF} / \mathrm{LZF}) / \partial\left(\Delta A / A_{0}\right)=30$, respectively], whereas $r_{C}$ reached its minimum value (down to $74 \pm 1 \%$ ). This corresponds to the formation of the steeply dipping preferential pathways that has already been stressed for dry filters (see "Monitoring of Straining Mechanisms in Dry Filters"). In other words, once most of the central zone cavities have been filled, the progress of fines within the central zone capillaries likely followed the course of adjoining preferential pathways $\left[\partial\left(F_{C}\right) / \partial\left(\Delta A / A_{0}\right)\right.$ derivative increased from 5,000 to $49 \times 10^{3}$ type $\mathrm{S}$ beads, while $\lambda_{C}$ peaked at $6.5 \pm 0.2$ layers: $\partial\left(\lambda_{C}\right) / \partial\left(\Delta A / A_{0}\right)=32$ layers]. Finally, at $15<\Delta A / A_{0}<65 \%, \quad 65<\Delta A / A_{0}<100 \%$, and $>100 \%$, the straining mechanisms followed the sequence observed in dry filters: clogging then filling of preferential pathways $\left[r_{C}\right.$ markedly increased: $\left.\partial\left(r_{C}\right) / \partial\left(\Delta A / A_{0}\right)=30\right]$ and increased transfer of fines toward the lateral zone $(\mathrm{CZF} / \mathrm{LZF}$ ratio decreased from $4.3 \pm 0.7$ to $3.0 \pm 0.5)$ and surface cake formation $\left(\lambda_{C}\right.$ fell to close to zero value), respectively. The ability of the saturated filters to transfer the fines toward the lateral zone is consistently lower that of dry filters: at $\Delta A / A_{0}>100 \%, 34 \pm 6 \%$ versus $55 \pm 3 \%$ of fines that reached the filter were driven into the lateral zone, respectively.

\section{Data Synthesis and Perspectives}

The distribution of fines within the formed granular filters showed that straining was extensively driven by near-top fine-fine and/or fine-filter interactions. As they plunged into the filters' pore network, the fines were radially dispersed and in part transferred toward the lateral margins (mainly in the dry filters). The remaining central fraction underwent an intense straining (mainly in watersaturated filters). At depth (i.e., below the 1-3 uppermost layers), the pace of straining for both the dry and saturated filters converged and remained relatively unchanged. This pointed out the existence of a stationary state depicted by lower straining dynamics, longer straining lengths, and partial inflow of fines from the lateral margins.

The monitoring of straining process evidenced the existence of transient mechanisms that sequentially developed as a function of the amount of fines that reached the filters (Fig. 8). The proposed mechanisms were (1) the filling of accessible cavities that constitute filters' pore network, (2) the formation of steeply dipping preferential pathways, (3) the clogging and partial filling of the preferential pathways, and (4) the use of lateral unobstructed capillaries that augment with the formation of a surface cake. The occurrence and the development of such mechanisms likely depend on the nature of the granular filter. Hence, the dimensions of filters (the thickness and width) and the structure of their pore network as well as the nature of ongoing mechanisms must be properly appraised in order to accurately gauge the efficiency of straining.

The magnitude of the four identified stages and the amplitude of the corresponding straining mechanisms also depended on the presence or absence of water. In the hydrostatic experiments, pore water acted as a moderator. The viscous forces likely lowered the kinetic energy of fines and ultimately contributed to increase their retention. Accordingly, whereas the straining process was likely depicted by diffusionlike mechanisms in dry filters (lateral dispersion of fines due to the random bounces in pores), sedimentationlike mechanisms dominated in the water-saturated filters (lower lateral dispersion and marked deposition in the cavities). However, relatively low velocities for water sufficed to increase the dispersion of fines and guide them throughout the filters' pore network.

Overall, the proposed mechanisms and straining stages fit the experimental results and theoretical calculations. However, the exact nature of microstructural fine-fine and fine-filter interactions must be further probed by means of pores/constriction-scale 
Dry filters
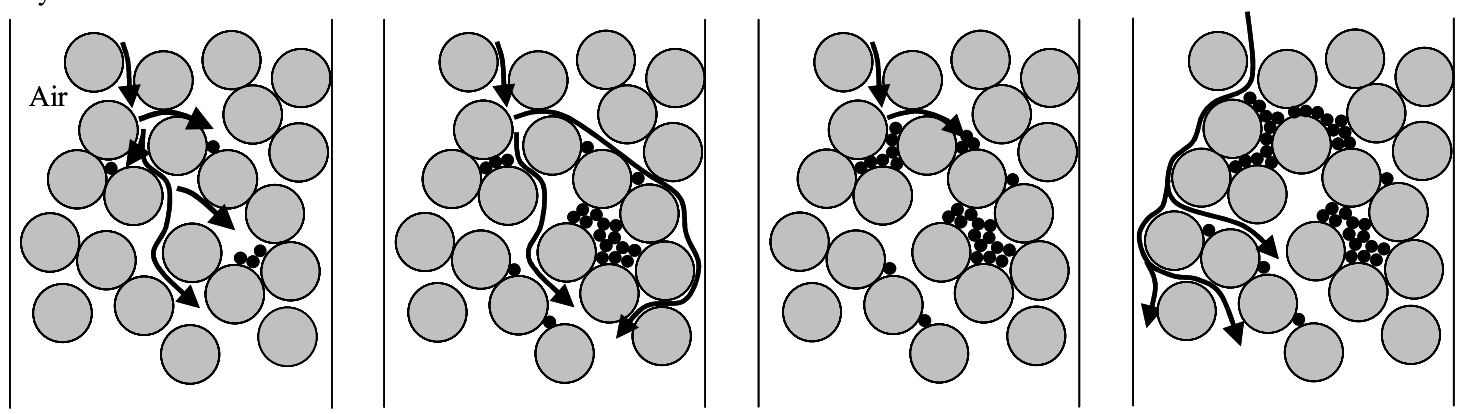

Water-saturated filters (hydrostatic)
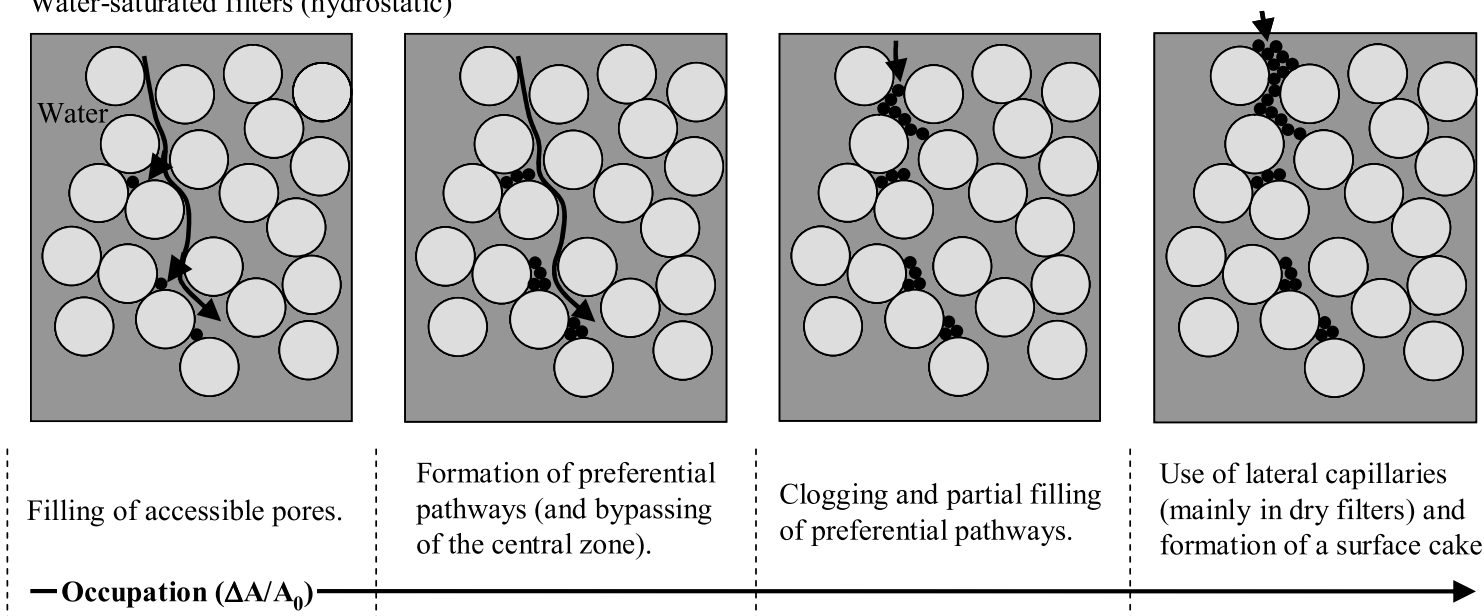

Formation of preferential pathways (and bypassing of the central zone).
Clogging and partial filling of preferential pathways.
Use of lateral capillaries

(mainly in dry filters) and

formation of a surface cake.

Fig. 8. Schematic view of the straining stages and associated mechanisms discussed in this study; distinction was made between the dry (top panels) and water-saturated (hydrostatic conditions, bottom panels) filters; a brief description of proposed mechanisms is displayed as a function of the occupation of the horizontal planes of maximum relative density

measurements [e.g., using Synchrotron X-ray microtomography techniques that provide three-dimensional (3D) representations of solids down to the micrometer] and/or validated by 3D numerical models (e.g., with discrete element method and multiscale lattice Boltzmann simulations in which the trajectories of fines are individually computed from their initial position and movement as well as relevant physical equations and contact laws). Finally, the role of several parameters like filter/fines grain size distribution and shape and the physicochemical properties of the pore fluids must be also carefully considered in order to advance the understanding of straining mechanisms in granular filters.

\section{Acknowledgments}

This research was financially supported by France's National Research Agency (ANR) through the TRANSOL (Multi Scale Modeling of Particle Transport in Soils) Project. The authors would like to thank M. A. Idrissi for her contribution to the experimental tests. The authors gratefully acknowledge S. Bonelli, P. Philippe, and E. Vincens for their constructive comments.

\section{References}

Amirtharajah, A. (1988). "Some theoretical and conceptual views of filtration." J. Am. Water Works Assoc., 80(12), 36-46.

Arun, K. (1970). "Numerical solution of filtration equations." J. Sanit. Engrg. Div., 96(2), 195-210.
Bai, R., and Tien, C. (2000a). "Effect of deposition in deep-bed filtration: Determination and search of rate parameters." J. Coll. Int. Sci., 231(2), 299-311.

Bai, R., and Tien, C. (2000b). "Transient behavior of particle deposition in granular media under various surface interactions." Coll. Surf. A., 165(1-3), 95-114.

Choo, C. U., and Tien, C. (1995a). "Simulation of hydrosol deposition in granular media." AIChE J., 41(6), 1426-1442.

Choo, C. U., and Tien, C. (1995b). "Analysis of the transient behavior of deep-bed filtration." J. Coll. Int. Sci., 169(1), 13-33.

Duval, H., Masson, D., Guillot, J. B., Schmitz, P., and D'humieres, D. (2006). "Two-dimensional lattice-Boltzmann model of hydrosol depth filtration." AIChE J., 52(1), 39-48.

Elimelech, M. (1994). "Particle deposition on ideal collectors from dilute flowing suspensions: Mathematical formulation, numerical solution, and simulations." Sep. Sci. Technol., 4(10), 186-212.

Elimelech, M., and O'Melia, C. R. (1990a). "Effect of particle size on collision efficiency in the deposition of Brownian particles with electrostatic energy barriers." Langmuir, 6(6), 1153-1163.

Elimelech, M., and O'Melia, C. R. (1990b). "Kinetics of deposition of colloidal particles in porous media." Environ. Sci. Technol., 24(10), $1528-1536$.

Fan, L. T., Nassar, R., Hwang, S. H., and Chou, S. T. (1985). "Analysis of deep-bed filtration data: Modelling as a 'birth-death process'." AIChE J., 31(11), 1781-1790.

Friedlander, S. K. (1958). "Theory of aerosol filtration." Ind. Eng. Chem., 50(8), 1161-1164.

Ganter, C. G., Jakob, S. M., and Takala, J. (2006). "Pulmonary capillary pressure-A review." Minerva Anest., 72(1-2), 21-36.

Ghidaglia, C., de Arcangelis, L., Hinch, E. J., and Guazzelli, E. (1996). "Hydrodynamic interactions in deep-bed filtration." Phys. Fluids, $8(1), 6-14$. 
Ghidaglia, C., Guazzelli, E., and Oger, L. (1991). "Particle penetration depth distribution in deep bed filtration." J. Phys. D, 24(11), 2111-2114.

Grace, H. P. (1956). "Structure and performance of filter media: Part 1 \& 2." AIChE J., 2(3), 307-336.

Harter, T., Wagner, S., and Atwill, E. R. (2000). "Colloid transport and filtration of Cryptosporidium parvum in sandy soils and aquifer sediments." Environ. Sci. Technol., 34(1), 62-70.

Ho, C.-C., and Zydney, A. L. (2000). "A combined pore blockage and cake filtration model for protein fouling during microfiltration." J. Colloid Interface Sci., 232(2), 389-399.

Hubbe, M. A. (2002). "Fines management for increased paper machines productivity." Proc., Sci. Technol. Adv., Pira, Leatherhead, UK.

Ives, K. J. (1960). "Rational design of filters." Proc., Inst. Civ. Eng., 16(2), $189-193$.

Ives, K. J. (1969). "Theory of filtration.” Int. Water Supply Congress, International Water Supply Association, London, UK.

Ives, K. J. (1970). "Rapid filtration.” Water Res., 4(3), 201-223.

Ives, K. J. (1975a). "Capture mechanisms in filtration.” The scientific basis of filtration, K. J. Ives, ed., Noordhoff International, Laden, Holland, 183-201.

Ives, K. J. (1975b). "Mathematical models of deep bed filtration." The scientific basis of filtration, K. J. Ives, ed., Noordhoff International, Laden, Holland, 218-234.

Ives, K. J. (1989). "Filtration studies with endoscopes.” Water Res., 23(7), 861-866.

Iwasaki, T. (1937). "Some notes on sand filtration." J. Am. Water Works Assoc., 29(5), 1591-1602.

Johnson, W. P., Ma, H., and Pazmino, E. (2011). "Straining credibility: A general comment regarding common arguments used to infer straining as the mechanism of colloid retention in porous media." Environ. Sci. Technol., 45(9), 3831-3832.

Kau, S. M., and Lawler, D. F. (1995). "Dynamics of deep-bed filtration: Velocity, depth, and media." J. Environ. Eng., 121(12), 850-859.

Lance, J. C., and Gerba, C. P. (1982). "Virus removal with land filtration." Water Reuse, E. J. Middlebrooks, ed., Butterworth, Stoneham, MA, 641-660.

Lee, J., and Koplik, J. (2001). "Network model for deep bed filtration." Phys. Fluids, 13(5), 1076-1078.

Liu, Y., Yang, C. H., and Li, J. (2007). "Influence of extracellular polymeric substances on pseudomonas aeruginosa transport and deposition profiles in porous media." Environ. Sci. Technol., 41(1), 198-205.

Logan, B. E., Jewett, D. G., Arnold, R. G., and Bouwer, E. J. (1995). "Clarification of clean-bed filtration models." J. Environ. Eng., 121(12), 869-873.

McCarthy, J. F., Sanford, W. E., and Stafford, P. L. (1998). "Lanthanide field tracers demonstrate enhanced transport of transuranic radionuclides by natural organic matter." Environ. Sci. Technol., 32(24), 3901-3906.

Mintz, D. M. (1966). "Modern theory of filtration.” Proc., 7th Congress Int. Water Supply Association, Vol. 1, International Water Supply Association, London, UK, 3-29.

Moran, D. C., Moran, M. C., Cushing, R. S., and Lawler, D. F. (1993a). "Particle behavior in deep-bed filtration: Part 1. Ripening and breakthrough." J. Am. Water Works Assoc., 85(12), 69-81.

Moran, M. C., Moran, D. C., Cushing, R. S., and Lawler, D. F. (1993b). "Particle behavior in deep-bed filtration: Part 2. Particle detachment." J. Am. Water Works Assoc., 85(12), 82-93.

Muresan, B., Saiyouri, N., Guefrech, A., and Hicher, P.-Y. (2011). "Internal erosion of chemically reinforced granular materials: A granulometric approach." J. Hydrol., 411(3-4), 178-184.

Odira, P. M. A. (2002). "Computer simulation of orthokinetic flocculation in a filterbed." J. Civ. Eng., 7(1), 67-82.

Oger, L. (1987). "Etude des corrélations structure-propriétés dans les milieux granulaires modèles." Ph.D. thesis, Rennes 1 Univ., Rennes.

O'Melia, C. R. (1965). "Discussion of 'Theory of water filtration' by T.R. Camp.” J. Sanit. Eng. Div., 91(2), 92-98.
O'Melia, C. R., and Ali, W. (1978). "The role of retained particles in deep bed filtration." Prog. Water Technol., 10(5-6), 167-182.

Payatakes, A. C., Rajagopalan, R., and Tien, C. (1974). "Application of porous media models to the study of deep filtration." Can. J. Chem. Eng., 52(6), 722-731.

Payatakes, A. C., Park, H. Y., and Petrie, J. (1981). "A visual study of particle deposition and reentrainment during depth filtration of hydrosols with a polyelectrolyte." Chem. Eng. Sci., 36(8), 1319-1335.

Pazmino, E. F., Ma, H., and Johnson, W. P. (2011). "Applicability of colloid filtration theory in size-distributed, reduced porosity, granular media in the absence of energy barriers." Environ. Sci. Technol., 45(24), 10401-10407.

Pensdse, H., Tien, C., and Turian, R. M. (1978). "Dispersion measurement in clogged filters beds-A diagnostic study on morphology of particles deposits." AIChE J., 24(3), 473-485.

Rajagopalan, R., and Tien, C. (1976). "Trajectory analysis of deep-bed filtration with the sphere-in-a-cell porous media model." AIChE J., 22(3), 523-533.

Rajagopalan, R., and Tien, C. (1977). "Experimental analysis of particle deposition on single collectors." Can. J. Chem. Eng., 55(3), 256-264.

Rege, S. D., and Fogler, H. S. (1988). "A network model for deep bed filtration of solid particles and emulsion drops." AIChE J., 34(11), $1761-1772$

Ryan, J. N., and Elimelech, M. (1996). "Colloid mobilization and transport in groundwater." Colloids Surf., A., 107(20), 1-56.

Shapiro, A. A., Bedrikovetsky, P. G., Santos, A., and Medvedev, O. O. (2007). "A stochastic model for filtration of particulate suspensions with incomplete pore plugging." Transp. Porous Med., 67(1), 135-164.

Sharma, M. M., and Yortsos, Y. C. (1987). "A network model for deep bed filtration processes." AIChE J., 33(10), 1644-1653.

Simunek, J., He, C. M., Pang, L. P., and Bradford, S. A. (2006). "Colloidfacilitated solute transport in variably saturated porous media: Numerical model and experimental verification." Vadose Zone J., 5(3), 1035-1047.

Stanley, D. R. (1955). "Sand filtration studied with radiotracers." J. Sanit. Eng. Div., 81(1), 592-596.

Stein, S., and Tomas, J. (2012). "Modelling of the filtration behaviour using coupled DEM and CFD." Discrete element modelling of particulate media, W. Chuan-Yu, ed., Royal Society of Chemistry, Cambridge, UK, 113-120.

Stevenson, D. G. (1997). "Flow and filtration through granular mediaThe effect of grain and particle size dispersion." Water Res., 31(2), 310-322.

Tien, C. (1989). Granular filtration of aerosols and hydrosols, Butterworth Publishing, Boston.

Tien, C., and Payatakes, A. C. (1979). "Advances in deep bed filtration." AIChE J., 25(5), 737-759.

Tobiason, J. E., and Vigneswaran, B. (1994). "Evaluation of a modified model for deep bed filtration." Water Res., 28(2), 335-342.

Ushiki, K., and Tien, C. (1984). "In situ observation of aerosol filtration in a two dimensional model filter." AIChE Series, 80(241), $137-148$

Vigneswaran, S., and Song, C. J. (1986). "Mathematical modelling of the entire cycle of deep bed filtration." Water Air Soil Pollut., 29(2), 155-164.

Vigneswaran, S., and Tulachan, R. K. (1988). "Mathematical modelling of transient behaviour of deep bed filtration." Water Res., 22(9), $1093-1100$

Yao, K.-M., Habibian, M. T., and O’Melia, C. R. (1971). "Water and waste water filtration: Concepts and applications." Environ. Sci. Technol., 5(11), 1105-1112.

Yao, K. M., and O'Melia, C. R. (1968). "Particle transport in aqueous flow through porous media." Proc., 16th Annual Conf. of the Hydraulic Division, ASCE, Reston, VA.

Yongwon, J., and Tien, C. (1992). "Increase in collector efficiency due to deposition in polydispersed granular filtration-An experimental study.” J. Aerosol Sci., 23(5), 525-537. 
Yoon, J. S., Culligan, P. J., and Germaine, J. T. (2006). "Visualisation of particle behaviour within a porous medium: Mechanisms for particle filtration and retardation during downward transport." Water Resour. Res., 42(6), 1-16.

Yoshida, H., and Tien, C. (1985). "Dynamic behavior of aerosol filtration in a two dimensional filter." Aerosol Sci. Technol., 4(4), 365-381.
Zamani, A., and Maini, B. (2009). "Flow of dispersed particles through porous media-Deep bed filtration." J. Petrol. Sci. Eng., 69(1-2), $71-88$.

Zhu, H. P., Zhou, Z. Y., Yang, R. Y., and Yu, A. B. (2007). "Discrete particle simulation of particulate systems: Theoretical development." Chem. Eng. Sci., 62(13), 3378-3396. 